\title{
Distinct roles and requirements for Ras pathway signaling in visceral versus somatic muscle founder specification
}

Yiyun Zhou' ${ }^{1}$, Sarah E. Popadowski ${ }^{1}$, Emily Deustchman ${ }^{1}$, and Marc S. Halfon ${ }^{1,2,3,4,5, *}$

${ }^{1}$ Department of Biochemistry, ${ }^{2}$ Department of Biological Sciences, ${ }^{3}$ Department of Biomedical Informatics, University at Buffalo-State University of New York, Buffalo NY 14203

${ }^{4} \mathrm{NY}$ State Center of Excellence in Bioinformatics and Life Sciences, Buffalo NY 14203

${ }^{5}$ Molecular and Cellular Biology Department and Program in Cancer Genetics, Roswell Park Comprehensive Cancer Center, Buffalo NY 14263

*Author for correspondence:

701 Ellicott St., Buffalo NY 14203

(716) 829-3126

mshalfon@buffalo.edu

running title: Ras signaling in muscle development

key words: myogenesis, signal integration, founder cell, muscle progenitor, fusion competent myoblast 
1

\section{SUMMARY}

3 A fundamentally different mechanism is shown for how Ras signaling governs cell fate

4 specification in the Drosophila somatic versus visceral mesoderms, providing insight into how $5 \quad$ signaling specificity is achieved.

\section{ABSTRACT} the ETS-domain downstream Ras effectors Pointed and Aop (Yan). We demonstrate here that for the circular visceral muscles, despite superficial similarities, a significantly different

12 specification mechanism is at work. Not only is visceral founder cell specification not dependent on Pointed or Aop, but Ras pathway signaling in its entirety can be bypassed. Our results show that de-repression, not activation, is the predominant role of Ras signaling in the visceral mesoderm and that accordingly, Ras signaling is not required in the absence of repression. The complex interplay between the Ras pathway, ETS transcription factors, and enhancer binding as a critical mechanism for determining unique responses to Ras signaling. 
23 Embryonic development requires that individual cells within a field acquire new, distinct fates.

24 The Drosophila larval musculature has emerged as an exemplary system for investigating this

25 process, revealing important insights into the acquisition of developmental competence,

26 progressive determination of cell fate, and the integration of multiple signals at the

27 transcriptional level. It has proven to be a particularly effective model for understanding how

28 specific outcomes can be obtained from the activation of the receptor tyrosine kinase

29 (RTK)/Ras/mitogen activated protein kinase (MAPK) signaling cascade (Halfon et al., 2000), a

30 highly pleiotropic pathway involved in numerous developmental processes and dysregulated in a

31 wide set of developmental disorders and cancers (Imperial et al., 2017, Schlessinger, 2000,

32 Tidyman and Rauen, 2009).

33 In the somatic (body wall) musculature, which has been studied the most extensively, individual

34 syncytial muscle fibers develop via the fusion of two cell types drawn from an initially

35 undifferentiated pool of myoblasts within the stage 10-11 (mid-embryogenesis) mesoderm: a

36 single "founder cell" (FC; itself the product of the asymmetric division of a muscle "progenitor")

37 and one or more "fusion competent myoblasts" (FCMs; Fig. 1) (for review see Dobi et al., 2015).

38 Whereas FCMs are uncommitted, FCs are induced with specific identities. FCMs fuse with FCs,

39 with the resulting syncytium maintaining the identity provided by the FC. FC specification is thus

40 the critical step in muscle development as the FC genetic program controls muscle size,

41 orientation, expression of cell-surface proteins, and the like. 
42 While multiple signaling pathways, including the Wg (Wnt) and Dpp (BMP) pathways, are 43 integrated to specify particular muscle fates, the key event in muscle determination is MAPK 44 activation via RTK/Ras pathway signaling (Buff et al., 1998, Carmena et al., 2002, Carmena et al., 45 1998, Halfon et al., 2000). In the somatic mesoderm the relevant receptors are the Drosophila EGF and FGF receptor homologs. Cells which are competent to respond to Ras/MAPK signaling are

47 induced as an equivalence group and subsequently restricted by lateral inhibition (mediated by Notch-Delta signaling) to a single muscle progenitor.

These events have been studied in detail at the molecular level in the context of the muscle identity 50 gene even skipped (eve). A 300 bp transcriptional enhancer directly integrates the inductive 51 Ras/MAPK signaling with a combination of additional signal-derived and tissue-specific TFs to 52 activate eve expression (Halfon et al., 2000). The Ras/MAPK effector is the ETS-domain TF Pnt, 53 which binds the enhancer at up to eight distinct sites (Boisclair Lachance et al., 2018, Halfon et 54 al., 2000). In the absence of induction these sites are bound by the ETS-domain repressor Aop 55 (also known as Yan) (Halfon et al., 2000, Webber et al., 2013, Boisclair Lachance et al., 2018).

56 Recent evidence suggests that Pnt bound at these or other sites may also contribute to repression 57 in the absence of MAPK activation (Webber et al., 2018). Importantly, experiments have shown 58 that induction trumps repression: in the absence of both Pnt and Aop binding, there is no gene 59 activation (Halfon et al., 2000 and unpublished data). Ectopic activation of the Ras/MAPK 60 pathway leads to ectopic FC formation in all competent cells, at the expense of FCMs; this has

61 been demonstrated at the level of the receptor tyrosine kinases (activated EGFR and FGFR), of 62 Ras (activated Ras), and of the effector (activated Pnt) (Carmena et al., 1998, Halfon et al., 2000). 
63 We focus here on the circular visceral muscle fibers, which surround the midgut and develop from

64 the trunk visceral mesoderm (for simplicity, we will refer to these simply as "visceral muscle" and

65 "visceral mesoderm," respectively). These muscle fibers appear to develop similarly to the somatic muscles (Fig. 1), with the exception that they are only binucleate and it is unclear whether there is

67 a "muscle progenitor" cell specified prior to visceral FC specification (Martin et al., 2001). As with somatic FCs, visceral FC specification occurs following MAPK activation-here via the single signaling pair of the Anaplastic lymphoma kinase (Alk) receptor tyrosine kinase and its

70 ligand Jellybelly (Jeb) — and just as for the somatic musculature, ectopic activation of the

71 Ras/MAPK pathway causes presumptive FCMs to be re-specified as FCs (Fig. 2B) (Englund et

72 al., 2003, Lee et al., 2003, Weiss et al., 2001). However, the details of these events have not been 73 established.

74 We now show that despite the apparent similarities between somatic and visceral FC

75 specification, fundamental differences exist with respect to the role of Ras/MAPK signaling in

76 specifying the FC fate. Unlike the positive inductive role for MAPK activity in the somatic

77 mesoderm, in the visceral mesoderm, MAPK activity is instead required to relieve repression of

78 FC fates, and the transcriptional effectors Pnt and Aop do not appear to play a significant role in

79 this process. Moreover, MAPK activity can be dispensed with entirely in the absence of the

80 FCM-specific transcription factor Lameduck (Lmd) or when repressor binding sites are mutated

81 in an FC-specific enhancer for the mib2 gene. Thus, unlike in the somatic mesoderm, Ras/MAPK

82 signaling is not essential for visceral FC specification. Our results illustrate how similar-

83 appearing developmental processes can result from different underlying molecular mechanisms

84 and provide fresh insights into how unique responses to Ras-pathway signaling are determined 85 within similar cellular and developmental contexts. 


\section{RESULTS}

Visceral founder cell specification is independent of the ETS-domain transcription factors

\section{Pnt and Aop}

90

91

92

In a previous screen for genes that respond differentially to different Ras-pathway components, we observed that despite responding to RTK and Ras activation, the FC gene mib2 is not regulated by the Ras effector Pnt in the visceral mesoderm (Leatherbarrow and Halfon, 2009). Expression of both mib2 RNA and a mib2-lacZ reporter gene driven by an FC-specific enhancer (mib2-FCenhancer) is normal in pnt null mutant embryos (Fig. 2C and Halfon et al., 2011), and expression of a constitutively active form of Pnt $\left(\mathrm{Pnt}^{\text {act }}\right)$ has no effect on expression of either the endogenous gene or the reporter (Fig. 2D and Leatherbarrow and Halfon, 2009). Similarly, mib2 expression in the visceral mesoderm is normal in embryos mutant for the ETS-domain repressor aop (yan) (Fig. 2E), and in response to expression of the constitutively-repressing version "yan ${ }^{a c t} "$ (Fig. 2F and Halfon et al., 2011). This raised the question of whether this is a mib2specific regulatory effect, or whether these two Ras effectors, which both play a significant role in somatic FC determination, are not required for visceral FC specification.

To test this, we assessed the expression of additional visceral FC and FCM markers in pnt null and/or pnt $t^{\text {act }}$ backgrounds. Expression of the somatic muscle identity gene even skipped (eve) was used as a control (data not shown), as its expression is respectively reduced or expanded in response to pnt loss and gain of function. Expression of the FC markers org-1, kirre (also known 
as dumbfounded (duf)), and RhoGAP15B all appear normal in a pnt ${ }^{a c t}$ background, whereas, as reported previously, expression of all three expands with pan-mesodermal expression of activated Ras (Ras ${ }^{\text {act}}$ ) (Fig. 3; Leatherbarrow and Halfon, 2009, Lee et al., 2003). Doublelabeling with antibodies to Biniou, a general visceral mesoderm marker (Zaffran et al., 2001), showed that the observed expansion is throughout the visceral mesoderm (Fig. 2B and data not shown). This suggests that non-FCs (i.e., FCMs) have been respecified as FCs, rather than that there has merely been increased FC proliferation. Consistent with this, expression of the FCM marker Lmd behaves in the reciprocal fashion: Lmd expression decreases in the visceral mesoderm with Ras $^{a c t}$ expression, but is unaffected in pnt null or pnt $t^{a c t}$ backgrounds (Fig. 3B, E, $\mathrm{H}$ and data not shown; Popichenko et al., 2013). Taken together, our results show that while Ras activity is sufficient to induce FC fates throughout the visceral mesoderm, neither pnt nor aop appear to play a significant role in this process.

\section{Visceral founder cell expression of mib2 is repressed through ETS-type binding sites in the mib2 FC enhancer}

Although mib2 expression in the visceral mesoderm is not dependent on either pnt or aop, the mib2_FCenhancer enhancer was identified in part based on the presence of ETS-type, putative Pnt binding sites (Philippakis et al., 2006). We showed previously that mutation of a set of seven ETS sequences in this enhancer caused an expansion of reporter gene expression driven by the mutated enhancer (Fig. 4E, F and Halfon et al., 2011). Like the expression observed with activation of the Ras pathway, the expanded reporter gene expression extends throughout the 
127 visceral myoblast population as marked by Bin expression (data not shown). Interestingly, 128 reporter gene expression is stronger in the FCs than in the rest of the myoblasts (Fig. 4G, Fig.

129 S1A and data not shown). Activated Ras expression restores full-strength reporter activity

130

131

132

133

similar to what is observed with the wild-type enhancer (Fig. 4H, Fig. S1B and data not shown).

However, as expected, the same disparity in reporter expression between FCs and non-FCs as seen in the wild-type background is seen with activated Pnt, which by itself does not lead to expanded mib2 expression (Fig. 4I, Fig. S1C and data not shown).

The expanded reporter gene expression observed upon mutation of the ETS sequences suggested that rather than being required for positively activating mib2 expression-as expected based on analogy to the requirement for Ras pathway signaling mediated by ETS-family transcription factors in the somatic mesoderm (Halfon et al., 2000)—mib2 is repressed via transcription factor binding at these sites. In order to better understand the nature of this repression, we decided to characterize the mib2 regulatory sequences more thoroughly.

Using sequence conservation with other Drosophila species as a guide, we first tested reporter gene activity with a truncated version of the mib2_FCenhancer containing a 5' 120 bp deletion (Fig. 4B, Fig. S2). The deleted region includes one of the putative Pnt binding sites previously mutated ("site 1", Fig. 4B, Fig. S2), as well as a non-canonical Pnt site suggested by protein binding microarray experiments (Fig. S2, "siteN"; personal communication from Alan Michelson). The resulting "mib2_FC626" enhancer has activity identical to the longer mib2_FCenhancer (Fig. 4C, D), responds to Ras ${ }^{a c t}$ and Pnt ${ }^{a c t}$ ectopic expression in the same manner (Fig. S1E, F and Leatherbarrow and Halfon, 2009), and shows a similar Ras act $_{\text {-like }}$ expansion of reporter gene expression when the remaining six ETS-type sequences are mutated 
149 (construct “'mib2_FC626 ETS; Fig. 4E, F, G). In contrast, a more extensive 5' 413 bp deletion (Fig.

150 4B arrowhead, Fig. S2, gray arrow) leads to a complete loss of visceral mesoderm activity and

151 only a limited residual expression elsewhere (data not shown). As the mib2_FC626 enhancer

152 behaves in all aspects like the original mib2_FCenhancer, we used this shorter sequence as a

153 template for further characterization of mib2 regulation.

154 We mutated the six remaining ETS-type sequences individually to determine which putative

155 binding sites were responsible for the expanded reporter gene expression (as sites 5 and 6 are

156 close together, we treated them initially as a single site5-6). Expanded reporter gene expression

157 was observed only with the site5-6 paired mutation (Fig. 4J, Fig. S3). We therefore further

158 dissected this pair to test its component individual sites. Mutation of site 5 led to expansion of

159 mib2_FC626 enhancer activity throughout the visceral mesoderm (Fig. 4K), while site 6 by itself

160 had a barely observable phenotype with expanded expression almost indistinguishable from

161 background (Fig. S1G). The expanded expression observed with the single site 5 mutation was

162 notably weaker than that observed with the paired site5-6 mutation, which itself had weaker

163 expression than the mib2_FC626 $6^{E T S}$ six-site-mutated enhancer (Compare Fig. 4G, J, and K).

164 While site 5 therefore appears to be the most critical site contributing to expanded mib2_FC626

165 expression, the stronger expression seen when multiple sites are mutated suggests that these

166 other sites are functional as well and contribute to overall enhancer activity. Consistent with their

167 more essential roles, site 5 is the most highly conserved of the six ETS sites in the mib2_FC626

168 sequence, followed by site 6 (Fig. S2B).

169 In addition to expanded visceral mesoderm expression, the mib2_FC626 $6^{\text {ETS }}$ construct drives 170 ectopic reporter gene expression in the midline of the ventral nerve cord (Fig. 4M-O and Halfon 
171 et al., 2011). This ectopic midline expression is also observed with the mib2_FC626 $6^{\text {site }}$ construct

172 (Fig. 4L), but not with any of the other single-site enhancer mutations. Similar ectopic mib2

173 expression is observed in aop null mutant embryos (Fig. 4P), suggesting that while Aop does not

174 regulate mib2 in the visceral mesoderm, it may act via this site to repress mib2 in the nervous

175 system.

179 for FC gene expression; for example, in the absence of both pnt and aop expression the eve_MHE FC enhancer is inactive, and mutation of the common ETS-type Pnt and Aop binding sites eliminates enhancer activity (Halfon et al., 2000). However, the de-repression of the mib2 visceral FC enhancer seen with ETS site mutation suggested that Ras activity, normally not present in the FCM population into which mib2 reporter gene expression expands, might be

184 dispensable when the mib2 enhancer is de-repressed. To test this, we analyzed the activity of the wild-type and mutated mib2_FC626 enhancers in a jeb null background, which lacks Ras signaling in the visceral mesoderm. Whereas the wild type mib2_FC626 enhancer is inactive in

187 the visceral mesoderm of jeb null embryos (Fig. 5A), the mib2_FC626 ${ }^{E T S}$ mutated enhancer is expressed throughout the visceral mesoderm just as in a wild type background (Fig. 5B, arrows).

189 Staining for the activated, di-phosphorylated form of MAPK confirmed that no signaling was present in the jeb null background (Fig. 5D). Unlike in the somatic mesoderm, therefore, Ras 
191 signaling is not required for expression of a visceral FC gene in the absence of ETS-site

192 mediated repression.

\section{Visceral FC specification can occur in the absence of Ras pathway signaling}

195 The expanded expression of an FC gene throughout the visceral mesoderm we observed in the case of the de-repressed mib2_FC626 enhancer is reminiscent of what has been observed upon loss of function of the FCM transcriptional activator Lmd. Popichenko et al. (2013) showed that in lmd null embryos, FC markers such as org-1, hand, and kirre expand throughout the visceral mesoderm, with reciprocal loss of FCM genes such as $\operatorname{Vrpl}$. This resembles the phenotype observed with Ras activation. In a similar fashion, lmd mutation leads to the conversion of a small subset of FCMs to adult muscle precursor and pericardial cells (Sellin et al., 2009). However, these phenotypes are in sharp contrast to what is observed for the bulk of the somatic mesoderm, where lmd loss of function has no effect on FC specification (Duan et al., 2001, RuizGomez et al., 2002). Interestingly, the FCM-specific gene sticks-and-stones (sns) remains expressed in the $l m d$ visceral mesoderm, suggesting that the observed FCM $\rightarrow \mathrm{FC}$ conversion is incomplete (Estrada et al., 2006, Ruiz-Gomez et al., 2002). Given our results with the mib2

207 enhancer, we wondered if $l m d$ loss-of-function induced FCM $\rightarrow$ FC respecification could also occur in the absence of Ras pathway activity. Therefore, we tested jeb; lmd double mutant embryos for a range of FC markers including org-1, mib2, and RhoGAP15B, which are 
212 null embryos no FC markers are expressed, expression in jeb; lmd embryos consistently

213 resembles $l m d$ alone, in most cases with expanded FC expression (Fig. 6). Surprisingly, mib2 and

214 RhoGAP15B, which expand throughout the visceral mesoderm both with Ras activation and

215 upon mutation of the mib2 FC enhancer, do not appear to have expanded expression in the $l m d$

216 background when assayed by in situ hybridization (Fig. 6B, 6F). This may be indicative of an

217 incomplete conversion of FCMs to FCs, consistent with the maintenance of sns expression in the

218 FCM region reported previously. Likewise, Wg expression also only expands to a few additional

219 cells and not throughout the entire width of the anterior PS8 visceral mesoderm (Fig. 6S). On the

220 other hand, we found that the mib2_FC626 reporter construct does show fully expanded

221 expression in lmd embryos (Fig. 6B'). As expression driven by the mib2_FC626 enhancer

222 appears identical to endogenous mib2 expression in all other contexts we have examined, it may

223 be that the lack of expanded mib2 expression observed in lmd embryos simply represents a

224 failure of detection, given that, similar to what we saw with the reporter construct in other

225 backgrounds, reporter gene expression in the FCM region is weaker than that in the native FC

226 region (Fig. S1D). Consistent with this interpretation, we see a modest widening of mib2

227 expression in the jeb; lmd embryos (Fig. 6D). Importantly, regardless of the exact degree of

228 expanded expression due to $l m d$ loss of function, FC expression of all tested genes is clearly

229 rescued in the jeb;lmd background, demonstrating the ability for Ras signaling to be bypassed in

230 the absence of lmd expression.

231 To ensure that the rescue of FC specification observed in jeb;lmd mutants is not the result of a

232 cryptic Ras signaling pathway activated by loss of $l m d$, we checked for the presence of activated

233 MAPK in the double-mutant embryos. As expected when jeb is absent, no activated MAPK is

234 observed, regardless of presence or absence of lmd (Fig. 6X, Y). 


\section{DISCUSSION}

237 Both somatic and visceral muscle development require as an initial step the specification of individual muscle founder cells from within the general myoblast pool. Superficially, the process appears alike for both tissues: FCs fail to form in the absence of RTK/Ras/MAPK signaling, and ectopic activation of the Ras pathway causes FCMs to be respecified as FCs. A striking aspect of our current results is that these seemingly similar events are brought about in a mechanistically opposite fashion in the somatic versus visceral mesoderms. Our work therefore serves to underscore how common developmental outcomes can derive from dramatically different gene

244 regulatory mechanisms.

245 In the somatic mesoderm, it has been well-established that positive induction via Ras/MAPK

246 signaling is essential for specifying FC fates (Buff et al., 1998, Carmena et al., 2002, Carmena et

247 al., 1998, Halfon et al., 2000). In the visceral mesoderm, however, repression has primacy over

248 induction. We demonstrate here that Ras/MAPK signaling acts in presumptive FCs to relieve

249 repression of the FC fate, while Popichenko et al. (2013) previously established that it serves to

250 prevent activation of FCM genes. The primary activator of FCM genes is Lmd, which prior to

251 FC specification is expressed in all visceral myoblasts (Ruiz-Gomez et al., 2002, Popichenko et

252 al., 2013). Ras/MAPK signaling in FCs causes phosphorylation of Lmd followed by its export

253 from the nucleus and its degradation, preventing it from activating FCM-specific genes such as

254 Vrpl (Popichenko et al., 2013). What happens at FC gene loci, however, had not previously been 255 determined. Our results with the mib2 enhancer demonstrate that FC genes can be activated in 256 the absence of Ras/MAPK signaling, through loss of repressor binding at the enhancer. 


\section{A model for FC fate specification}

258 The simplest model, taking into account our results and those of Popichenko et al. (2013), would

259 be for Lmd to function as both the FC gene repressor and the FCM gene activator; loss of Lmd

260 binding following Ras/MAPK signaling would thus simultaneously de-repress FC genes while

261 halting activation of FCM genes. Although Lmd is typically viewed as an activator, some

262 evidence suggests that it may also be capable of transcriptional repression (Cunha et al., 2010).

263 However, chromatin immunoprecipitation studies have repeatedly failed to detect appreciable

264 Lmd binding in the mib2 enhancer region (Busser et al., 2012, Cunha et al., 2010), and the mib2

265 enhancer lacks good candidate Lmd binding sites — particularly in the critical site5-site6 region

266 (MSH, unpublished results) — even when surveyed using a range of binding motifs derived from

267 multiple sources (Busser et al., 2012, Nitta et al., 2015, Zhu et al., 2011).

268 We therefore favor a basic model in which Lmd serves an activator of the FC gene repressor, such that loss of Lmd leads to loss of repressor activity in FCs and subsequent expression of FC

270 genes (Fig. 7). In wild type embryos, the main role of MAPK signaling is thus to cause

271 phosphorylation and degradation of Lmd, whereas in lmd mutant embryos, MAPK signaling

272 becomes irrelevant as Lmd is already absent. The repressor could also be a direct target of

273 MAPK, leading to its rapid displacement upon the onset of MAPK signaling (e.g., similar to

274 what happens with Aop at other loci (Rebay and Rubin, 1995)). This would be consistent with

275 the rapid timecourse of FC fate specification following MAPK activation. We surmise that there

276 are also additional, still unknown FC gene activators whose activity may or may not be MAPK

277 dependent. Tests of these various refinements to the basic model will require identification of the 278 FC gene repressor. 
279 In the somatic mesoderm, the repressor Tramtrack69 (Ttk69) appears to play a role as an $l m d-$ dependent FC gene repressor similar to what we posit here for visceral FC fate repression. $t$ tk69 expression is activated downstream of $l m d$ in FCMs, where it represses the transcription of FC genes (Ciglar et al., 2014). In FCs, Ttk69 is likely post-translationally degraded in a Rasdependent manner (Ciglar et al., 2014, Li et al., 1997), relieving repression of FC genes concurrent with Ras-dependent relief of Aop-mediated repression and induction via Pnt and/or other activators. However, different mechanisms appear to be at work in the visceral mesoderm. Although ttk69 mutants do display some altered visceral mesoderm gene expression (Ciglar et al., 2014), visceral FCs appear to be correctly specified and FC-specific genes such as mib2 are expressed in the appropriate pattern, without expansion into the FCM field (Ciglar et al., 2014; SEP, unpublished observations).

\section{A balance of ETS factors?}

Given the derepression phenotypes observed on mutation of the ETS sites in the mib2 enhancer, we favor the likelihood that the relevant repressor is a member of the ETS transcription factor

294 family, either by itself or working redundantly with Pnt and/or Aop. Several other ETS domain

295 proteins exist in Drosophila (Chen et al., 1992), although their expression patterns and mutant

296 phenotypes are for the most part not well defined. A role for additional ETS proteins was also

297 previously suggested for the dorsal somatic mesoderm, where pnt loss-of-function leads to a

298 partial loss of Eve-expressing FCs, but mutation of ETS binding sites completely eliminates

299 expression driven by the eve_MHE enhancer (Halfon et al., 2000). Although our data argue 
300

301

302

303

304

305

306

307

308

309

310

311

312

313

314

315

316

317

against an absolute requirement for either Pnt or Aop, we cannot rule out a more limited contribution from these factors. Indeed, chromatin IP experiments indicate that Pnt can bind to the mib2 enhancer region, although it is not known in what cell types (Webber et al., 2018), and aop mutants show an effect on mib2 expression in the ventral midline (Fig. 4P).

Although there is considerable evidence demonstrating the requirement for RTK/Ras/MAPK signaling for somatic FC specification, the molecular details on the mechanisms governing MAPK-dependent activation and repression come mainly from studies of a single transcriptional enhancer, eve_MHE (Boisclair Lachance et al., 2018, Halfon et al., 2000, Webber et al., 2018, Webber et al., 2013). It is clear that ETS-factor-dependent activation is essential for the activity of this enhancer, as mutation of the major ETS binding sites renders the enhancer non-functional (Halfon et al., 2000). However, recent studies suggest that instead of an abrupt switch between activation and repression due to mutually exclusive enhancer occupancy by Pnt and Aop, there is a more subtle balance between these transcription factors and their binding to the multiple highand low-affinity ETS binding sites found in the enhancer (Boisclair Lachance et al., 2018, Webber et al., 2018). Other somatic FC enhancers have not been rigorously tested with respect to ETS-family binding, and it may be that the trade-off between activation and repression differs among them. This would help to explain the results of Buff et al. (1998), who demonstrated that different FCs are specified at different levels of RTK/Ras signaling. One way to achieve such differential sensitivity would be through a mixture of activating versus repressing ETS transcription factors competing for binding at a range of high- and low-affinity sites. Such a mechanism could provide for exquisitely fine-tuned responsiveness to Ras/MAPK signaling, making this an appealing possibility. 
323 In this vein, we note that our detailed molecular insights for visceral FCs again come mainly

324 from the study of a single enhancer, mib2_FC626. Here, elimination of the major ETS binding

325 sites leads to increased activity, opposite the situation with the somatic eve_MHE enhancer.

326 However, preliminary analysis of other visceral FC enhancers suggests that eliminating ETS

327 binding sites can lead to loss of enhancer function, more similar to what is seen in the somatic

328 musculature (YZ, unpublished observations). Thus while our data from the mib2_FC626

329 enhancer as well as from analysis of $l m d$ mutants clearly establishes de-repression rather than

330 induction as the major role for Ras pathway signaling during visceral FC specification, it may be

331 that the molecular basis for how this signaling is modulated by ETS-family transcription factors

332 at the enhancer level is complex and balanced individually at each FC gene enhancer. Taken

333 together, these plus other recent results (Boisclair Lachance et al., 2018, Webber et al., 2018)

334 point to an elaborate interplay between Ras signaling, ETS transcription factors, and subtly tuned

335 binding sites, and highlight the need for detailed molecular studies of a more comprehensive set

336 of both somatic and visceral FC enhancers. 


\section{MATERIALS AND METHODS}

344

345

346

347

348

349

350

351

352

353

354

355

356

357

358

359

360

361

362

363

364

\section{Drosophila strains and genetics}

Oregon- $R$ was used as the wild type. Mutant stocks are described in FlyBase (Gramates et al., 2017) and include $p n t^{\Delta 88}, a o p^{1}, l m d^{1}$, and jeb ${ }^{576}$ (Weiss et al., 2001). mib2_FCenhancer-lacZ is

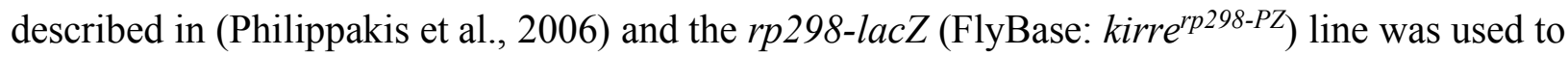
assess kirre (duf) expression (Nose et al., 1998). Ectopic expression was achieved using the Gal4-UAS system (Brand and Perrimon, 1993) and used lines Twi-Gal4 (FlyBase: P\{Gal4twi. $\left.G_{\}}\right)\left(\right.$Greig and Akam, 1993), UAS-Ras $1^{\text {Act }}$ (Carmena et al., 1998), UAS-PntP2VP16 (Halfon et al., 2000), and $U A S-y a n^{A c t}$ (Rebay and Rubin, 1995). Mutant lines were rebalanced over lacZmarked balancers to allow for genotyping of embryos.

\section{Immunohistochemistry and Microscopy}

Antibody staining was performed using standard Drosophila methods. The following primary antibodies were used: mouse $\alpha$ - $\beta$-galactosidase (Promega \#Z3783), 1:500; rabbit $\alpha$-GFP (Abcam ab290), 1:10000; rabbit $\alpha$-Bin (gift of Eileen Furlong), 1:300; rabbit $\alpha$-Lmd (gift of Hanh Nguyen), 1:1000; rat $\alpha$-Org-1 (gift of Manfred Frasch), 1:250; mouse $\alpha$-activated MAPK (diphosphorylated ERK1\&2; Sigma \#M9692), 1:250 (fixed in 8\% paraformaldehyde); mouse $\alpha$ Wg (4D4, Developmental Studies Hybridoma Bank), 1:100; mouse $\alpha$-con (C1.427, Developmental Studies Hybridoma Bank) 1:250. ABC kit (Vector Labs) was used for immunohistochemical staining. Differential interference contrast (DIC) microscopy was performed using a Zeiss Axioskop 2 microscope and Openlab (PerkinElmer) software for image capture. The following secondary antibodies were used for fluorescent staining: anti-mouse 
Alexa488 (Molecular Probes), 1:250; anti-mouse Alexa633 (Molecular Probes), 1:500; antirabbit Alexa488 (Molecular Probes), 1:250; anti-rabbit Alexa633 (Molecular Probes), 1:500; anti-rat Alexa633 (Molecular Probes), 1:500. Fluorescent staining was visualized by confocal microscopy using a Leica SP2 confocal microscope. In situ hybridization for detection of mib2 and RhoGAP15B transcripts was as previously described (Leatherbarrow and Halfon, 2009). Color and brightness of acquired images were adjusted using Adobe Photoshop.

\section{Site-directed mutagenesis and transgenesis:}

Mutagenesis of the mib2 enhancer was performed by overlap-extension PCR (Ho et al., 1989). Mutated sequences are shown in Fig. S2 (primer sequences available on request). Transgenic flies were generated by Genetic Services Inc. (Cambridge, MA) using phiC31-transgenesis and the attP2 landing site.

\section{ACKNOWLEDGEMENTS}

We thank Manfred Frasch, Eileen Furlong, Alan Michelson, Hanh Nguyen, the Bloomington Drosophila Stock Center (NIH P40OD018537) and the Developmental Studies Hybridoma Bank (created by the NICHD of the NIH and maintained at The University of Iowa, Department of Biology, Iowa City, IA 52242) for fly stocks and antibodies. Elizabeth Brennan, Sam Hasenauer, 
Qiyun Zhu, and Jack Leatherbarrow helped with experiments. Steve Gisselbrecht and Michael

Buck provided critical comments on the manuscript.

Competing Interests: No competing interests declared

Funding: This work was supported by the American Cancer Society [grant RSG-09-097-01-

DDC to MSH] and by the Biochemistry Department of the University at Buffalo.

\section{REFERENCES}

BILDER, D. \& SCOTT, M. P. 1998. Hedgehog and wingless induce metameric pattern in the Drosophila visceral mesoderm. Dev Biol, 201, 43-56.

BOISCLAIR LACHANCE, J. F., WEBBER, J. L., HONG, L., DINNER, A. R. \& REBAY, I. 2018. Cooperative recruitment of Yan via a high-affinity ETS supersite organizes repression to confer specificity and robustness to cardiac cell fate specification. Genes Dev, 32, 389-401.

BRAND, A. \& PERRIMON, N. 1993. Targeted gene expression as a means of altering cell fates and generating dominant phenotypes. Development, 118, 401-415.

BUFF, E., CARMENA, A., GISSELBRECHT, S., JIMENEZ, F. \& MICHELSON, A. M. 1998. Signalling by the Drosophila epidermal growth factor receptor is required for the specification and diversification of embryonic muscle progenitors. Development, 125, 2075-86.

BUSSER, B. W., HUANG, D., ROGACKI, K. R., LANE, E. A., SHOKRI, L., NI, T., GAMBLE, C. E., GISSELBRECHT, S. S., ZHU, J., BULYK, M. L., OVCHARENKO, I. \& MICHELSON, A. M. 2012. Integrative analysis of the zinc finger transcription factor Lame duck in the Drosophila myogenic gene regulatory network. Proc Natl Acad Sci US $A, 109,20768-73$.

CARMENA, A., BUFF, E., HALFON, M. S., GISSELBRECHT, S., JIMENEZ, F., BAYLIES, M. K. \& MICHELSON, A. M. 2002. Reciprocal regulatory interactions between the Notch and Ras signaling pathways in the Drosophila embryonic mesoderm. Dev Biol, 244, 226-42.

CARMENA, A., GISSELBRECHT, S., HARRISON, J., JIMÉNEZ, F. \& MICHELSON, A. M. 1998. Combinatorial signaling codes for the progressive determination of cell fates in the Drosophila embryonic mesoderm. Genes Dev., 12, 3910-3922. 
CHEN, T., BUNTING, M., KARIM, F. D. \& THUMMEL, C. S. 1992. Isolation and characterization of five Drosophila genes that encode an ets-related DNA binding domain. Dev Biol, 151, 176-91.

CIGLAR, L., GIRARDOT, C., WILCZYNSKI, B., BRAUN, M. \& FURLONG, E. E. 2014. Coordinated repression and activation of two transcriptional programs stabilizes cell fate during myogenesis. Development, 141, 2633-43.

CUNHA, P. M., SANDMANN, T., GUSTAFSON, E. H., CIGLAR, L., EICHENLAUB, M. P. \& FURLONG, E. E. 2010. Combinatorial binding leads to diverse regulatory responses: Lmd is a tissue-specific modulator of Mef2 activity. PLoS Genet, 6, e1001014.

DOBI, K. C., SCHULMAN, V. K. \& BAYLIES, M. K. 2015. Specification of the somatic musculature in Drosophila. Wiley Interdiscip Rev Dev Biol, 4, 357-75.

DUAN, H., SKEATH, J. B. \& NGUYEN, H. T. 2001. Drosophila Lame duck, a novel member of the Gli superfamily, acts as a key regulator of myogenesis by controlling fusioncompetent myoblast development. Development, 128, 4489-500.

ENGLUND, C., LOREN, C. E., GRABBE, C., VARSHNEY, G. K., DELEUIL, F., HALLBERG, B. \& PALMER, R. H. 2003. Jeb signals through the Alk receptor tyrosine kinase to drive visceral muscle fusion. Nature, 425, 512-6.

ESTRADA, B., CHOE, S. E., GISSELBRECHT, S. S., MICHAUD, S., RAJ, L., BUSSER, B. W., HALFON, M. S., CHURCH, G. M. \& MICHELSON, A. M. 2006. An Integrated Strategy for Analyzing the Unique Developmental Programs of Different Myoblast Subtypes. PLoS Genetics, 2, e16.

GRAMATES, L. S., MARYGOLD, S. J., SANTOS, G. D., URBANO, J. M., ANTONAZZO, G., MATTHEWS, B. B., REY, A. J., TABONE, C. J., CROSBY, M. A., EMMERT, D. B., FALLS, K., GOODMAN, J. L., HU, Y., PONTING, L., SCHROEDER, A. J., STRELETS, V. B., THURMOND, J. \& ZHOU, P. 2017. FlyBase at 25: looking to the future. Nucleic Acids Res, 45, D663-D671.

GREIG, S. \& AKAM, M. 1993. Homeotic genes autonomously specify one aspect of pattern in the Drosophila mesoderm. Nature, 362, 630-632.

HALFON, M. S., CARMENA, A., GISSELBRECHT, S., SACKERSON, C. M., JIMENEZ, F., BAYLIES, M. K. \& MICHELSON, A. M. 2000. Ras pathway specificity is determined by the integration of multiple signal-activated and tissue-restricted transcription factors. Cell, 103, 63-74.

HALFON, M. S., ZHU, Q., BRENNAN, E. R. \& ZHOU, Y. 2011. Erroneous attribution of relevant transcription factor binding sites despite successful prediction of cis-regulatory modules. BMC Genomics, 12, 578.

HO, S. N., HUNT, H. D., HORTON, R. M., PULLEN, J. K. \& PEASE, L. R. 1989. Site-directed mutagenesis by overlap extension using the polymerase chain reaction. Gene, 77, 51-9.

IMPERIAL, R., TOOR, O. M., HUSSAIN, A., SUBRAMANIAN, J. \& MASOOD, A. 2017. Comprehensive pancancer genomic analysis reveals (RTK)-RAS-RAF-MEK as a key dysregulated pathway in cancer: Its clinical implications. Semin Cancer Biol. 
LEATHERBARROW, J. R. \& HALFON, M. S. 2009. Identification of receptor-tyrosine-kinasesignaling target genes reveals receptor-specific activities and pathway branchpoints during Drosophila development. Genetics, 181, 1335-45.

LEE, H. H., NORRIS, A., WEISS, J. B. \& FRASCH, M. 2003. Jelly belly protein activates the receptor tyrosine kinase Alk to specify visceral muscle pioneers. Nature, 425, 507-12.

LI, S., LI, Y., CARTHEW, R. W. \& LAI, Z. C. 1997. Photoreceptor cell differentiation requires regulated proteolysis of the transcriptional repressor Tramtrack. Cell, 90, 469-78.

MARTIN, B. S., RUIZ-GOMEZ, M., LANDGRAF, M. \& BATE, M. 2001. A distinct set of founders and fusion-competent myoblasts make visceral muscles in the Drosophila embryo. Development, 128, 3331-8.

NITTA, K. R., JOLMA, A., YIN, Y., MORGUNOVA, E., KIVIOJA, T., AKHTAR, J., HENS, K., TOIVONEN, J., DEPLANCKE, B., FURLONG, E. E. \& TAIPALE, J. 2015. Conservation of transcription factor binding specificities across 600 million years of bilateria evolution. Elife, 4.

NOSE, A., ISSHIKI, T. \& TAKEICHI, M. 1998. Regional specification of muscle progenitors in Drosophila: the role of the msh homeobox gene. Development, 125, 215-23.

PHILIPPAKIS, A. A., BUSSER, B. W., GISSELBRECHT, S. S., HE, F. S., ESTRADA, B., MICHELSON, A. M. \& BULYK, M. L. 2006. Expression-Guided In Silico Evaluation of Candidate Cis Regulatory Codes for Drosophila Muscle Founder Cells. PLoS Computational Biology, 2, e53.

POPICHENKO, D., HUGOSSON, F., SJOGREN, C., DOGRU, M., YAMAZAKI, Y., WOLFSTETTER, G., SCHONHERR, C., FALLAH, M., HALLBERG, B., NGUYEN, H. \& PALMER, R. H. 2013. Jeb/Alk signalling regulates the Lame duck GLI family transcription factor in the Drosophila visceral mesoderm. Development, 140, 3156-66.

REBAY, I. \& RUBIN, G. M. 1995. Yan functions as a general inhibitor of differentiation and is negatively regulated by activation of the Ras1/MAPK pathway. Cell, 81, 857-866.

RUIZ-GOMEZ, M., COUTTS, N., SUSTER, M. L., LANDGRAF, M. \& BATE, M. 2002. myoblasts incompetent encodes a zinc finger transcription factor required to specify fusion-competent myoblasts in Drosophila. Development, 129, 133-41.

SCHLESSINGER, J. 2000. Cell Signaling by Receptor Tyrosine Kinases. Cell, 103, 211-225.

SELLIN, J., DRECHSLER, M., NGUYEN, H. T. \& PAULULAT, A. 2009. Antagonistic function of Lmd and Zfh1 fine tunes cell fate decisions in the Twi and Tin positive mesoderm of Drosophila melanogaster. Dev Biol, 326, 444-55.

TIDYMAN, W. E. \& RAUEN, K. A. 2009. The RASopathies: developmental syndromes of Ras/MAPK pathway dysregulation. Curr Opin Genet Dev, 19, 230-6.

WEBBER, J. L., ZHANG, J., MASSEY, A., SANCHEZ-LUEGE, N. \& REBAY, I. 2018. Collaborative repressive action of the antagonistic ETS transcription factors Pointed and Yan fine-tunes gene expression to confer robustness in Drosophila. Development. 
509

510

511

WEBBER, J. L., ZHANG, J., MITCHELL-DICK, A. \& REBAY, I. 2013. 3D chromatin interactions organize Yan chromatin occupancy and repression at the even-skipped locus. Genes Dev, 27, 2293-8.

WEISS, J. B., SUYAMA, K. L., LEE, H. H. \& SCOTT, M. P. 2001. Jelly belly: a Drosophila LDL receptor repeat-containing signal required for mesoderm migration and differentiation. Cell, 107, 387-98.

ZAFFRAN, S., KUCHLER, A., LEE, H. H. \& FRASCH, M. 2001. biniou (FoxF), a central component in a regulatory network controlling visceral mesoderm development and midgut morphogenesis in Drosophila. Genes Dev, 15, 2900-15.

ZHU, L. J., CHRISTENSEN, R. G., KAZEMIAN, M., HULL, C. J., ENUAMEH, M. S., BASCIOTTA, M. D., BRASEFIELD, J. A., ZHU, C., ASRIYAN, Y., LAPOINTE, D. S., SINHA, S., WOLFE, S. A. \& BRODSKY, M. H. 2011. FlyFactorSurvey: a database of Drosophila transcription factor binding specificities determined using the bacterial onehybrid system. Nucleic Acids Res, 39, D111-7.

\section{FIGURE LEGENDS}

\section{Figure 1: Overview of Drosophila muscle development}

In both the somatic mesoderm (top) and trunk visceral mesoderm (bottom), initially equivalent myoblasts (left panel) are fated to become either muscle founder cells (FCs; middle panel, gray, red, and blue) or fusion competent myoblasts (FCMs; middle panel, yellow). FCs have specific identities, represented here by different colors, conferred by the activity of "identity genes" active in the FCs. FCMs fuse with FCs to generate individual muscle fibers (right panel), with each fiber maintaining the fate provided by the founder cell.

\section{Figure 2: mib2 expression responds to Ras signaling but not to pnt or aop}


521 All panels show stage 11 embryos stained for expression of Mib2 (using the mib2_FCenhancer

522 LacZ reporter, green) and the pan-visceral-mesoderm marker Biniou (Bin, magenta). The

523 exception is panel C, which shows only mib2 RNA by means of in situ hybridization. (A) Wild

524 type embryo depicted ventral side up and anterior to the left. The yellow box marks the

525 representative segments shown in panels B-G. (B) Wild-type showing Mib2-lacZ expression

526 confined to a single row of visceral mesodermal cells, the FCs. (C) In Twi-Gal4>UAS-Ras ${ }^{\text {act }}$

527 embryos, Mib2-lacZ expression expands throughout the visceral mesoderm. Bin-negative

528 clusters in the foreground are somatic mesoderm. In contrast, mib2 and Mib2-lacZ expression

529 remains restricted to a single layer of cells corresponding to the FCs, as in wild type, in both a

530 pnt null (D) and an activated pnt (E) background. Similarly, Mib2-lacZ expression retains a wild-

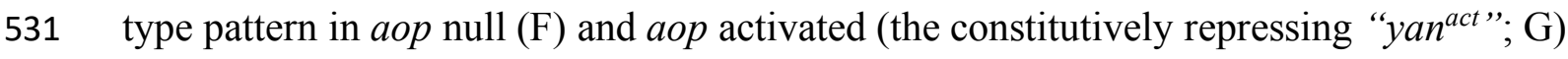

532 backgrounds.

\section{pnt}

536 Stage 11 embryos that are either wild type (A-C), have pan-mesodermal expression of activated

537 Ras (D-F; “twi $>$ Ras ${ }^{a c t}$ ”), or have pan-mesodermal expression of activated Pnt (G-I;

538 "twi>pnt $t^{a c t}$ ") were stained for FC and/or FCM markers. Consistent with results assessing mib2

539 expression, Ras activation led to increased FC and decreased FCM populations, while Pnt

540 activation had no effect. Panels A, D, and G show expression of Org-1, an FC marker; B, E, and

541 H depict the FC marker kirre ${ }^{r p 298-P Z}$, an enhancer-trap in the kirre (duf) locus (green), and FCM 
542

543

544

545

546

547

548

549

550

551

552

553

554

555

556

557

558

559

560

561

562

563

marker Lmd (magenta); and C, F, and I picture in situ hybridization to RhoGAP15B RNA. All embryos are oriented dorsal up and anterior to the left.

Figure 4: Mutagenesis of the mib2 FC enhancer reveals repression acting via ETS binding sites

(A) Schematic of the mib2 locus. The location of the intronic mib2_FCenhancer regulatory sequence is indicated in gray. (B) The mib2_FCenhancer regulatory sequence, with conservation shown below in green. The gray portion of the sequence is deleted in the mib2_FC626 constructs. A red arrowhead marks the location of the region deleted in the inactive 413 bp 5' deletion. Red bars numbered 1-7 indicate the positions of the tested ETS binding sites.

Conservation track shows the 27-insect PhastCons conservation from the UCSC Genome Browser. (C) The shorter mib2-FC626 enhancer (magenta) has activity indistinguishable from the original mib2_FCenhancer enhancer (green); a higher magnification view can be seen in (D). (E, F) Mutation of the 6 ETS binding sites in the mib2-FC626 enhancer (" $m i b 2-F C 626^{E T S}$, green) causes an expansion of reporter gene expression throughout the visceral mesoderm. Expression in the FCs is stronger than the ectopic FCM-domain expression (G). In contrast, pan-mesodermal Ras activation causes similar ectopic expression, but reporter gene levels are consistent throughout the visceral mesoderm $(\mathrm{H})$. Expression of activated Pnt, however, resembles the expression seen in a wild-type background (I). (J) Mutation of ETS sites 5 and 6 (" $m i b 2$ FC626 $6^{\text {site5-6") }}$ causes reporter gene expression to expand into the FCM domain, but the expanded expression is considerably weaker than that seen with the full 6-site mutation (compare with panel G). (K) Mutation of site 5 alone ("mib2-FC626sites") also causes a weak reporter gene 
571 background (arrows).

expansion. The yellow dotted line indicates the border of the FCM domain, as assessed by twocolor imaging for the pan-visceral mesoderm marker Biniou (not shown). (L) Mutation of site 7 ("mib2-FC626sit7”) has no effect in the visceral mesoderm (not shown), but leads to ectopic reporter gene expression in the midline of the ventral nerve cord (arrows). Similar ectopic expression is observed when all ETS sites are mutated (M, N, arrows; compare to the same locations marked by arrows with the wild-type enhancer in panel O). (P) Similar ectopic reporter gene expression in the ventral midline is also seen with the wild-type enhancer in a aop mutant

Figure 5: The mutated mib2 enhancer is active even in the absence of Ras signaling

574 (A) The wild-type ("mib2-FC626 WT") and (B) ETS-site mutated ("mib2-FC626"ETS") mib2

575 enhancers were crossed into a jeb null background that lacks Ras signaling in the visceral

576 mesoderm and assessed for reporter gene expression. Trunk visceral mesoderm expression is

577 absent for the wild-type enhancer, with only somatic mesoderm (arrows) and caudal visceral

578 mesoderm (arrowheads) activity still present. However, robust visceral mesoderm activity

579 resembling that seen in a wild-type background is observed with the mutated enhancer (B,

580 arrows). This expression resembles that seen with the wild-type enhancer following ectopic Ras

581 activation (compare with Figure 2B). (C) Staining for activated MAPK (dpMAPK) shows

582 crescents of visceral mesoderm expression in wild type embryos (arrows), which are absent in 583 jeb null embryos (D). Embryos are oriented ventral up and anterior to the left. 
Expression of the FC genes mib2 (A-D), RhoGAP15B (E-H), Org-1 (I-L), con (M-P), wg (Q-U), and activated $M A P K(\mathrm{~V}-\mathrm{Y})$ was assessed in wild type, lmd, jeb, and jeb;lmd double mutant embryos. Embryos in panels A-P and V-Y are oriented ventral up and anterior to the left and are shown as either whole embryos or as three-segment closeups (two segments in V-Y). Panel Q is oriented with ventral to the bottom and anterior to the left; the arrow points to the region shown in close up in panels R-U. (A) In situ hybridization for mib2 RNA. (A') Reporter gene expression driven by the mib2_FC626 enhancer. (B) In the lmd mutant background, mib2 RNA expression resembles wild type, but the reporter construct (B') has expanded expression similar to that seen with Ras activation or ETS site mutation. (C) Visceral mesoderm expression of mib2 is absent in jeb embryos but (D) is restored and mildly expanded in the jeb;lmd background.

RhoGAP15B expression (E) does not show expansion in lmd embryos (F), but is likewise absent in $j e b(\mathrm{G})$ and restored in a jeb;lmd $(\mathrm{H})$ mutant background. (I-L) Org-1 expression expands in lmd $(\mathrm{J})$, is lost in jeb $(\mathrm{K})$, and is restored in jeb;lmd $(\mathrm{L})$ embryos. (M-P) The same is true for Con, although expression remains confined to its wild-type anterior-posterior domain. (Q) Wg is expressed in a single visceral muscle FC in the wild type stage 11 embryo (arrow). Higher magnification views reveal that the cell number is increased in lmd (S, arrows) and jeb;lmd (U, arrows) mutant embryos, but $\mathrm{Wg}$ expression is absent in the jeb null background (T). (V-Y) Staining for activated (di-P) MAPK confirms that MAPK activation is normal in $l m d$ embryos (W) but absent in the jeb (X) and jeb;lmd (Y) visceral mesoderms. Arrows indicate visceral mesoderm expression, asterisks mark MAPK activation in the tracheal pits.

\section{Figure 7: A model for visceral founder cell specification}


608

609

610

611

612

613

614

615

616

617

618

619

620

621

622

623

624

625

626

627

628

629

In FCMs (left), Lmd activates FCM-specific genes as well as an FC-gene repressor, which keeps FC-specific genes shut off. In FCs (right), activation of MAPK leads to the degradation of Lmd, preventing activation of both the FCM genes and the FC-gene repressor. MAPK may also act directly on the FC-gene repressor (dotted line). Loss of repression allows for expression of the FC genes, possibly in conjunction with additional activators (not pictured).

\section{SUPPLEMENTAL FIGURES}

\section{Supplemental Figure S1: Responsiveness of the mib2_FC626 wild type and mutated}

\section{enhancers}

Greyscale (A-G), pseudocolored (A'-D'), and thresholded (A''-D') images of reporter gene expression in three segments of the stage 11 visceral mesoderm. Pseudocolored image show red $=$ brighter and blue $=$ dimmer expression. Thresholded images have had any pixels of less than one-half maximum intensity removed and the remaining pixels reset to maximum brightness. (A) mib2_FC626 $6^{E T S}$ reporter gene expression in cells specified as FCs (arrow) is stronger than the expression that expands into the FCM domain (arrowhead). (B) In an activated Ras background, however, reporter gene expression in both the native FC and FCM regions has similar strength. Reporter gene expression in the activated Pnt background (C) resembles that in the wild-type background, with FC-region expression stronger than that in the FCM region. (D) Reporter gene expression driven by the mib2_FC626 $6^{W T}$ enhancer in a $l m d$ mutant embryo. Expression in the FCM domain is weaker than that in the native FC domain. (E) The mib2 FC626 ${ }^{W T}$ enhancer responds to pan-mesodermal expression of activated Ras and of activated Pnt (F) identically to what is observed with the longer mib2FC_enhancer regulatory sequence (compare with Fig. 2). 
630 (G) Weak but perceptible expansion of reporter gene expression is seen with the mib2_FC626 site6

631 enhancer. The yellow dotted line indicates the limit of the FCM domain as determined through

632 double-labeling for the visceral mesoderm marker Biniou.

634 Supplemental Figure S3: mib2_FC626 ETS site mutations other than sites 5 and 6 have no

635 visceral FC phenotype.

636 Each panel depicts reporter gene expression in three segments of the visceral mesoderm, with

637 expression driven by the wild-type mib2_FC626 in green and one of the ETS-site mutants in

638 magenta. Mutations in sites 5 and 6 are shown in Fig. 4. Mutation of each of the individual sites

639 site2 (A), site3 (B), site4 (C), and site7 (D) have no effect on FC expression. For effects of site7

640 in the nervous system, see Fig. 4L.

641

642

643

644 
bioRxiv preprint doi: https://doi.org/10.1101/347526; this version posted June 14, 2018. The copyright holder for this preprint (which was not certified by peer review) is the author/funder, who has granted bioRxiv a license to display the preprint in perpetuity. It is made available under aCC-BY-ND 4.0 International license.

\section{Figure 1}

\section{Somatic mesoderm}

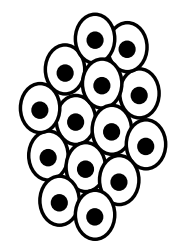

Undifferentiated mesoderm

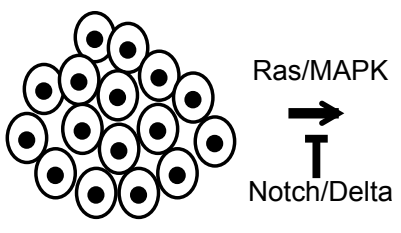

Visceral mesoderm
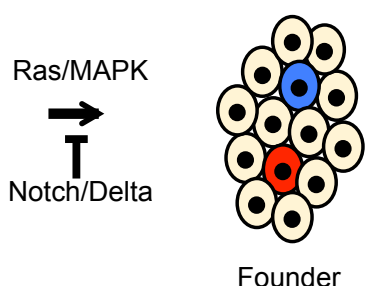

specification

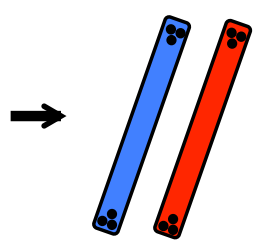

Fusion and

fiber formation
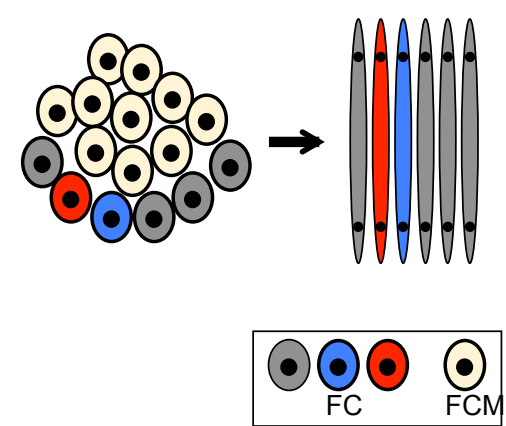
bioRxiv preprint doi: https://doi.org/10.1101/347526; this version posted June 14, 2018. The copyright holder for this preprint (which was not certified by peer review) is the author/funder, who has granted bioRxiv a license to display the preprint in perpetuity. It is made available under aCC-BY-ND 4.0 International license.

Figure 2
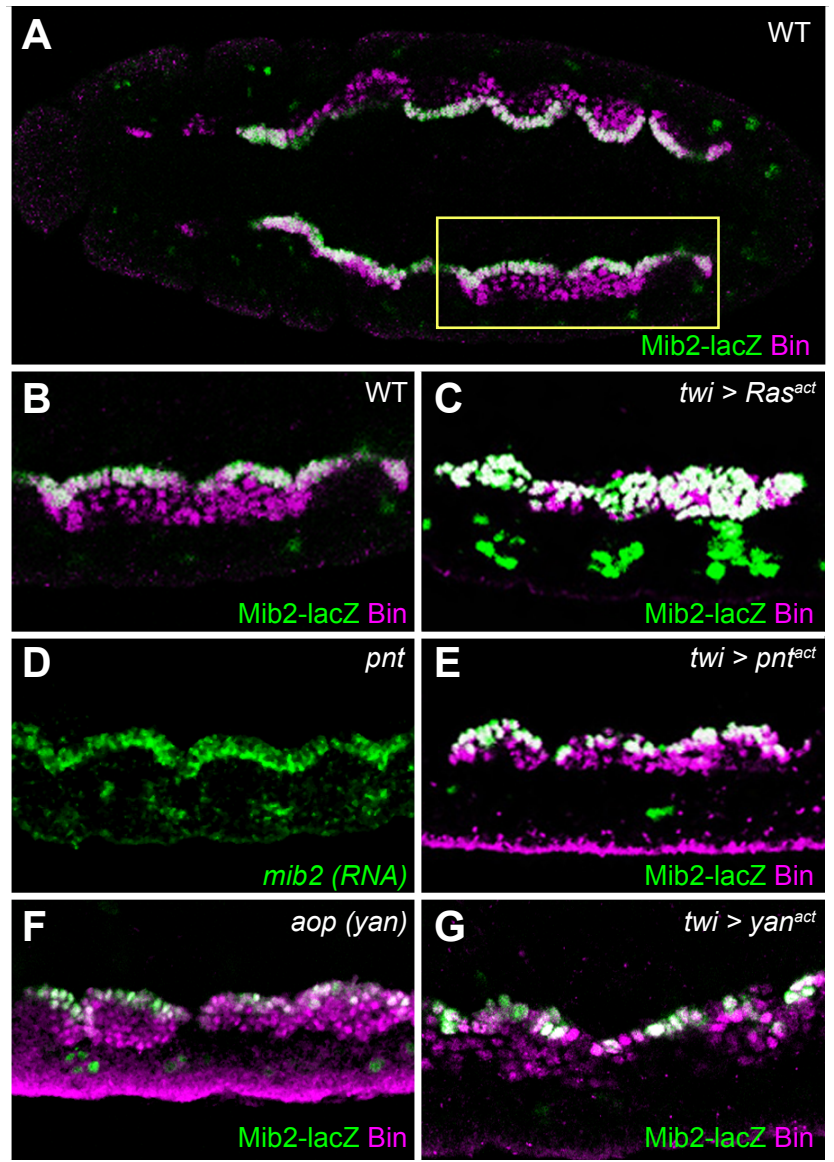
bioRxiv preprint doi: https://doi.org/10.1101/347526; this version posted June 14, 2018. The copyright holder for this preprint (which was not certified by peer review) is the author/funder, who has granted bioRxiv a license to display the preprint in perpetuity. It is made available under aCC-BY-ND 4.0 International license.

\section{Figure 3}
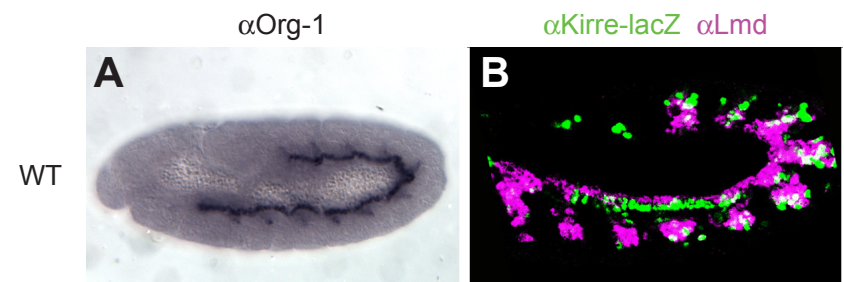

RhoGAP15B (RNA)
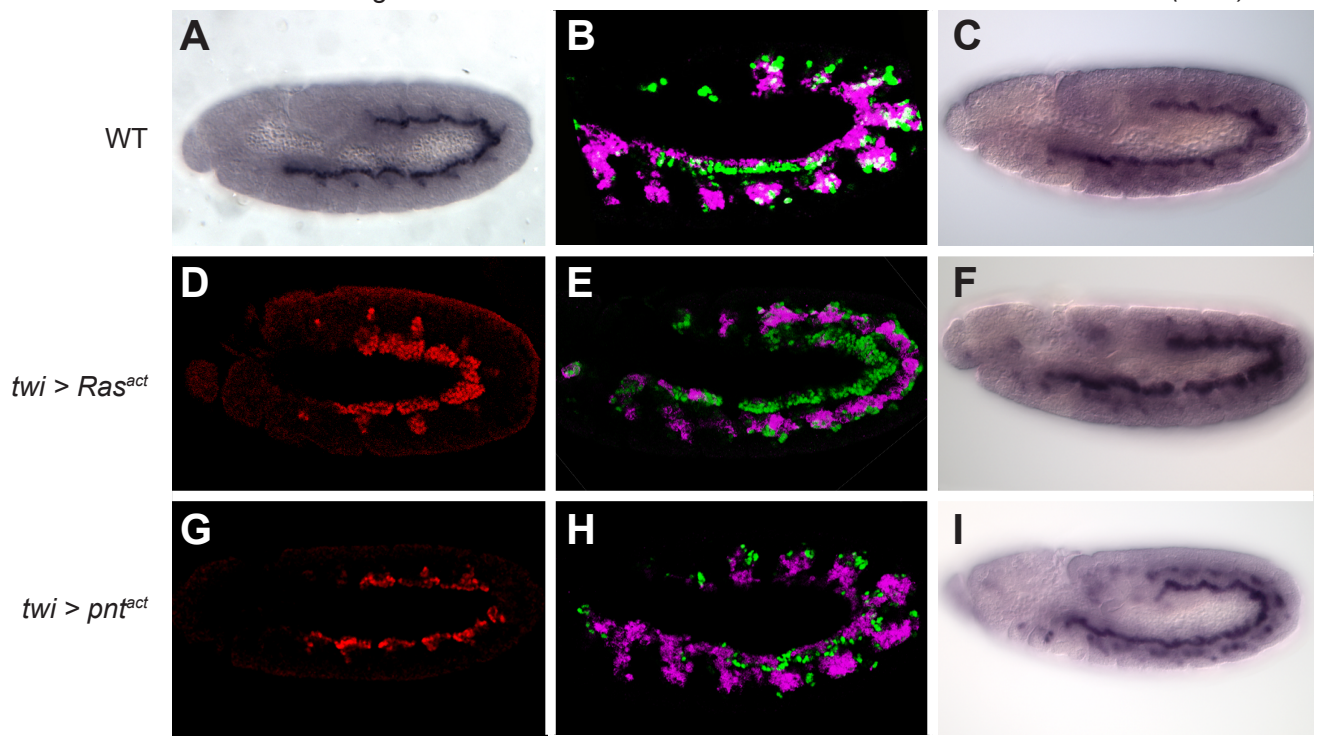
bioRxiv preprint doi: https://doi.org/10.1101/347526; this version posted June 14, 2018. The copyright holder for this preprint (which was not certified by peer review) is the author/funder, who has granted bioRxiv a license to display the preprint in perpetuity. It is made available under aCC-BY-ND 4.0 International license.

A
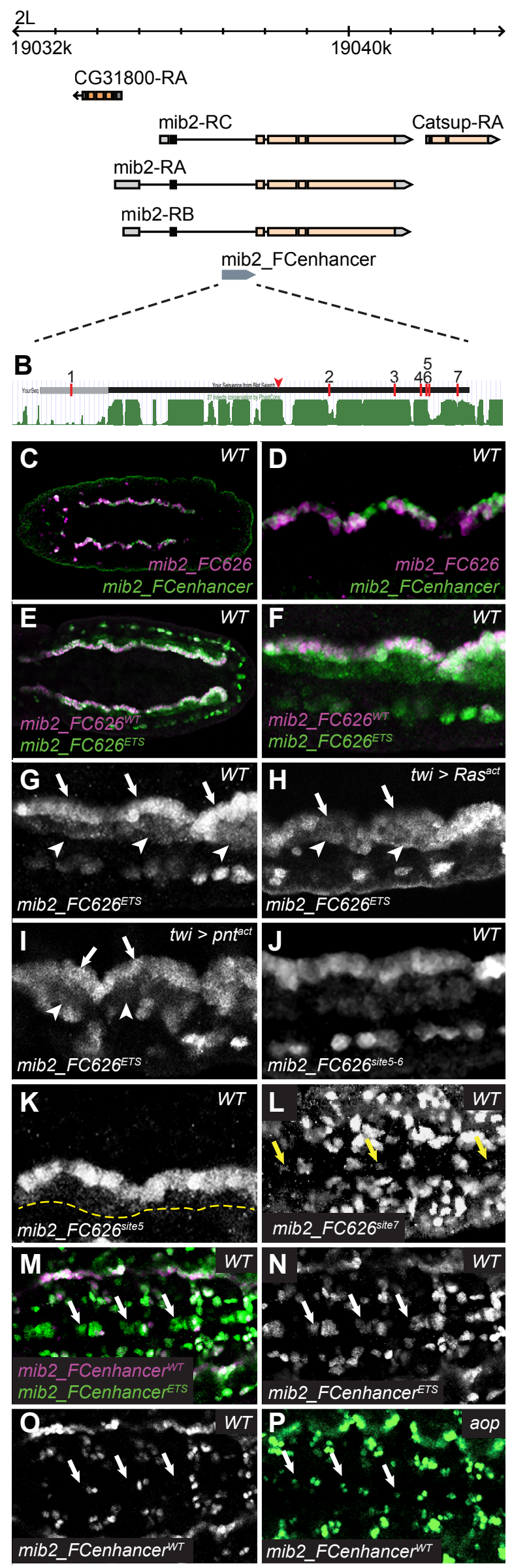
bioRxiv preprint doi: https://doi.org/10.1101/347526; this version posted June 14, 2018. The copyright holder for this preprint (which was not certified by peer review) is the author/funder, who has granted bioRxiv a license to display the preprint in perpetuity. It is made available under aCC-BY-ND 4.0 International license.

Figure 5

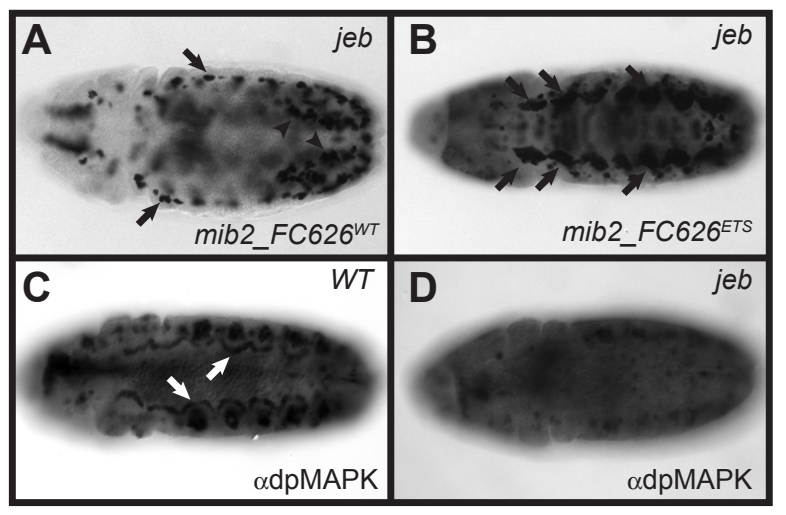


bioRxiv preprint doi: https://doi.org/10.1101/347526; this version posted June 14,2018 . The copyright holder for this preprint (which was not certified by peer review) is the author/funder, who has granted bioRxiv a license to display the preprint in perpetuity. It is made available under fig6 aCC-BY-ND 4.0 International license.

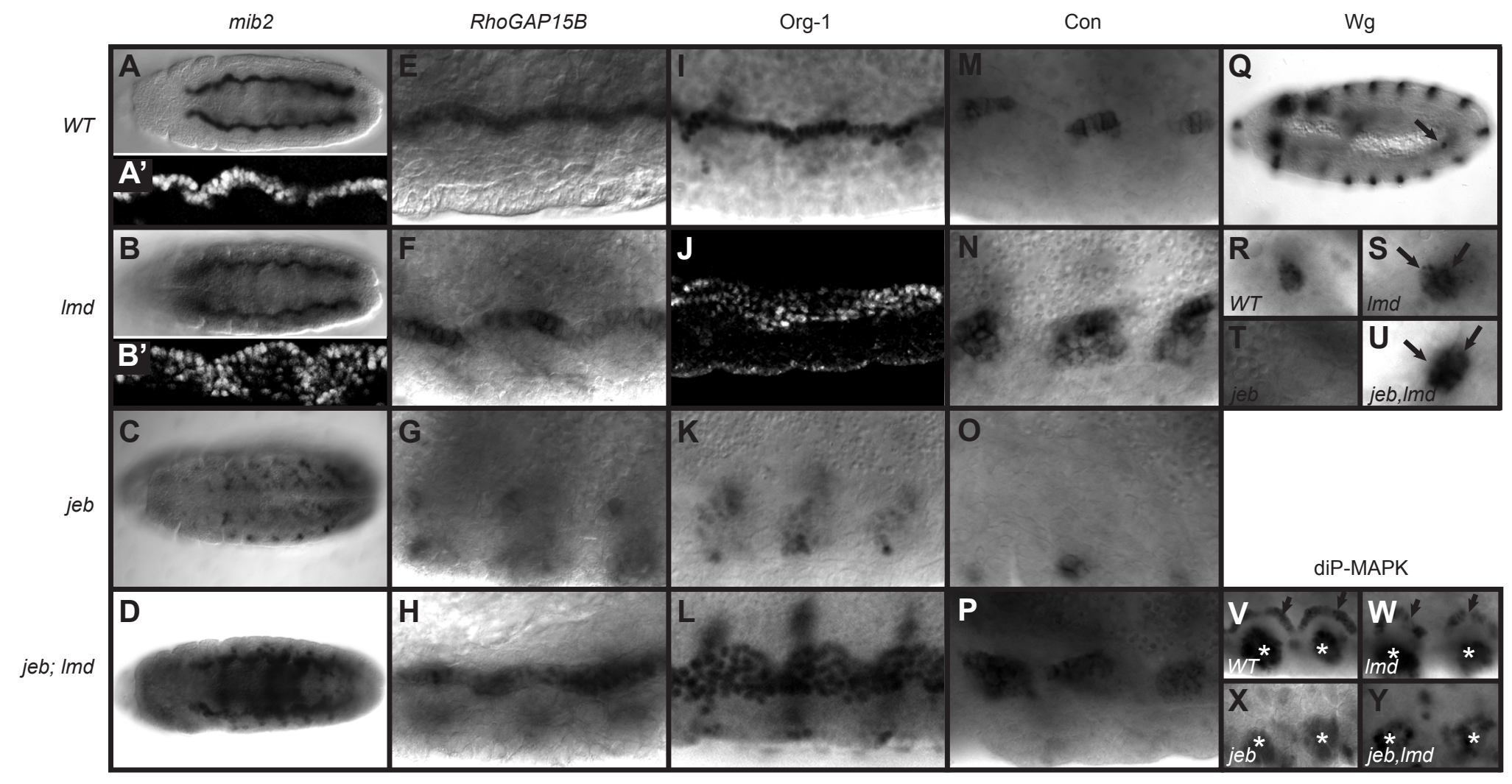


bioRxiv preprint doi: https://doi.org/10.1101/347526; this version posted June 14, 2018. The copyright holder for this preprint (which was not certified by peer review) is the author/funder, who has granted bioRxiv a license to display the preprint in perpetuity. It is made available under aCC-BY-ND 4.0 International license.

Figure 7

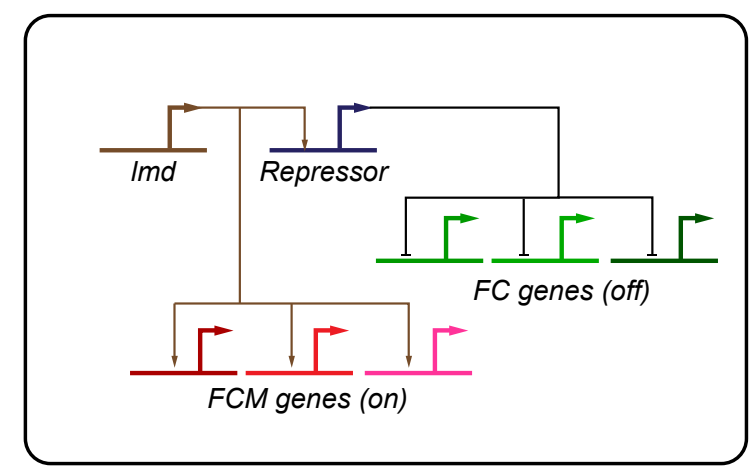

FCM

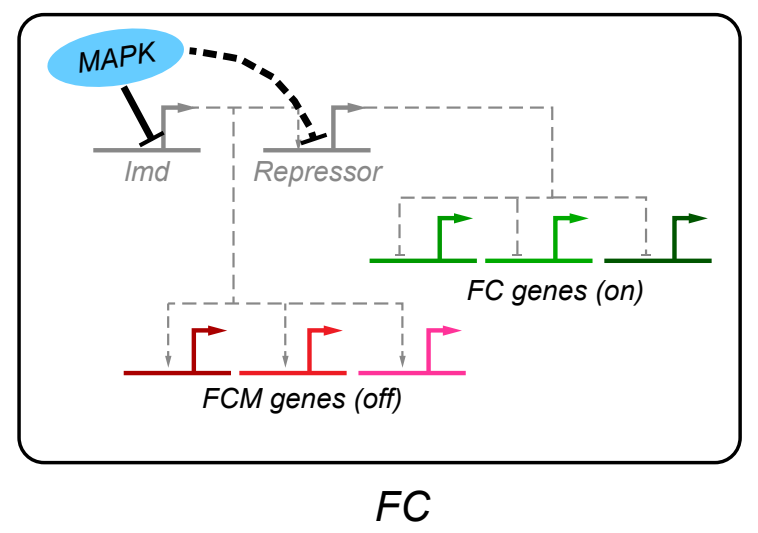


bioRxiv preprint doi: https://doi.org/10.1101/347526; this version posted June 14,2018 . The copyright holder for this preprint (which was not certified by peer review) is the author/funder, who has granted bioRxiv a license to display the preprint in perpetuity. It is made available under Figure S1
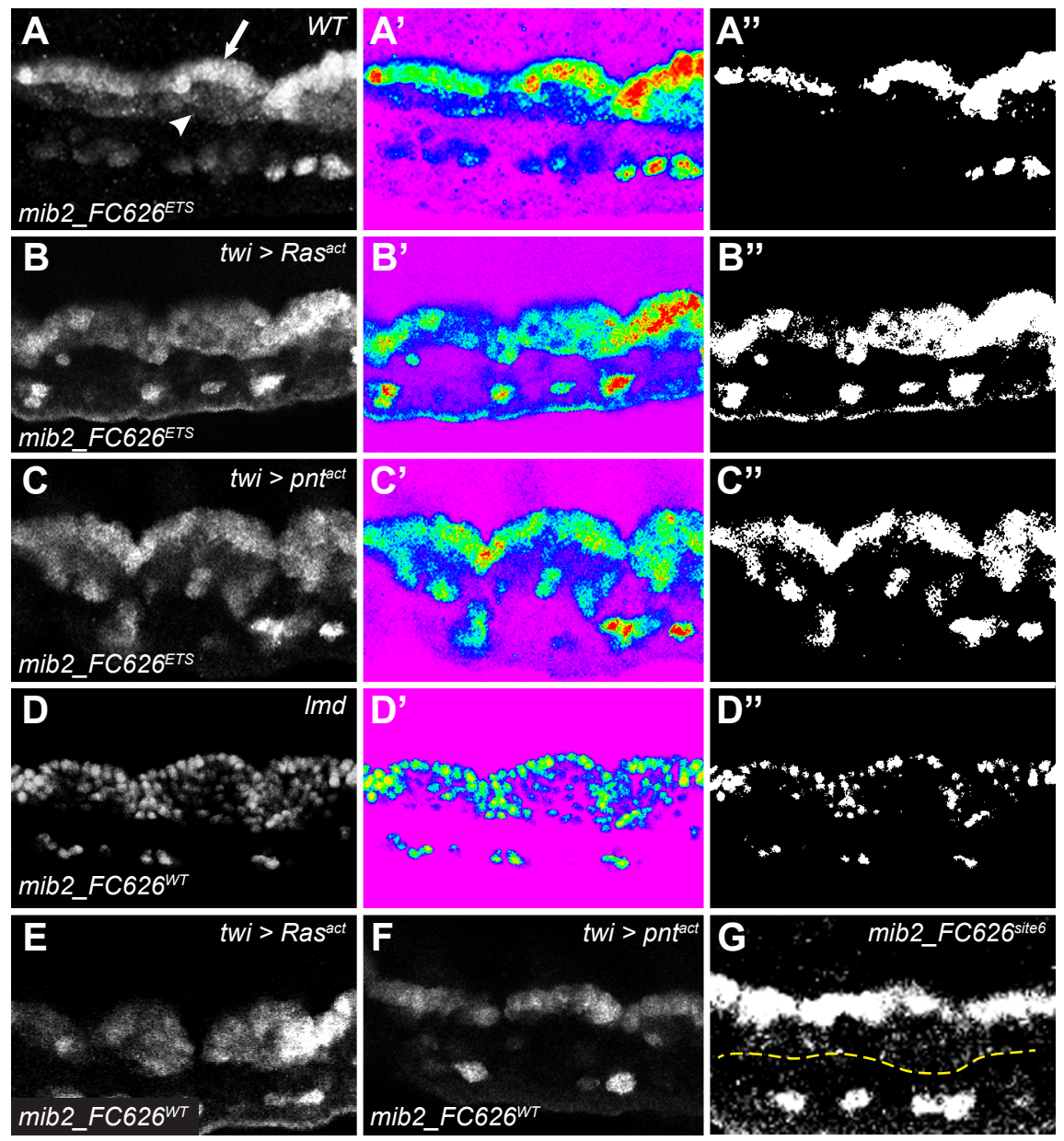


\begin{abstract}
A
siten site1

CCAAGAGAGAACATTTCTTCAGATACACTTCAAAAACAATTTGAATCATTTTGTGGAAGTTAAA

CG

CCAATCACCAAAGCCTAATTTGATATAAACGCAGTAATGTTTAAGCCTATTGAAGGATCGATC

CTATTAAAgCAgCTGCACACGTTTAgGATTAgGTCATGGTATGTGTTCCCCCCTCCCCAAGTCG

CCCTATTCCAGCCTGTGCAGCGAATGCATATGCACATGTCAGGCGCTAGGGCGCGTGCCATTTT

GTCTCCAАССтTTTTTGAgTGTTTATTTTTAGTTACACGGGTGGGGATCGCGAGCAGTTACAC

AGCTCCAGCCGGCCTGATATTTGGGGACGATGTGGAGAGTTTATTTTTGGACCTTGGTATTCCT

CCGACTGGGGTGTGTTGAAAATAGACATAAACAAATTTTCAGATGGGAGCCCAGCCATCGGTGC 1

site2

TCCCATTCCTCCCCAGGCCAACATCAAATGTCACCCTCTAGAGAACGATTCCACATCCACACCC

GTGATACGGGGTAATTATAGAGCAGCTGCACGCCCGAGTCCGAGTGCATAACAAAAATCCGCTT

site3

GGAGCCCGAGCCCGAGTCAATGATTATGGGTATTTATAGTCACGGCGCGTTGTTTATGAGGGGG

site4 site5 site6

AAGTGTGCGCTCTGCATATGTCTGATATCCACCGGATGTGGATGTGGGGATGGTGATGCCGATG

$\begin{array}{llll}\text { site7 } & \text { CG } & \text { CG CG }\end{array}$

TACACACAATGCAGCCCTAGGAGCATCCTTGTGGCAGCTCTATAGC
\end{abstract}

mib2_FCenhancer: chr2L:19036996..19037741 (r6/dm6)

B

$\begin{array}{cr}\text { site } & \text { PhastCons s } \\ & 0.0315 \\ 2 & 0.0639 \\ 3 & 0.1172 \\ 4 & 0.5486 \\ 5 & 0.9790 \\ 6 & 0.8285 \\ 7 & 0.0770\end{array}$

Supplementary Figure 2. Summary of putative ETS binding sites in the mib2_FCenhancer. (A) Sequence of the mib2 enhancer. ETS motifs are underlined with the substituted basepairs for the mutated enhancer shown in red. Site "N" indicates the non-canonical putative binding site derived from protein microarray data. The 5' $120 \mathrm{bp}$ deletion is highlighted in gray; gray arrow marks the site of the $413 \mathrm{bp}$ deletion. (B) PhastCons scores for each of the seven ETS sites (from the UCSC Genome Browser). 
bioRxiv preprint doi: https://doi.org/10.1101/347526; this version posted June 14, 2018. The copyright holder for this preprint (which was not certified by peer review) is the author/funder, who has granted bioRxiv a license to display the preprint in perpetuity. It is made available under aCC-BY-ND 4.0 International license.

\section{Figure S3}
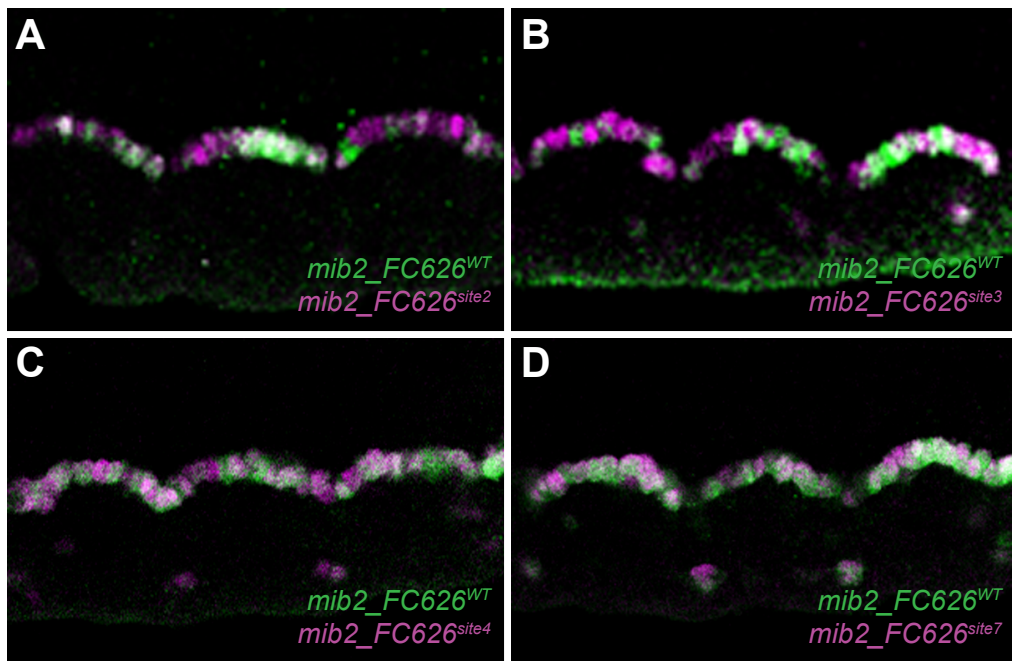